\title{
EFEITO DE DIFERENTES FONTES ENERGÉTICAS NA PREDISPOSIÇÃO PARA UROLITÍASE EM CABRITOS
}

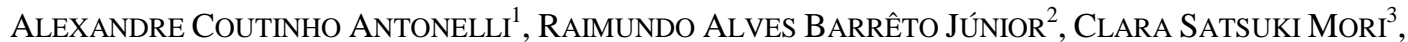

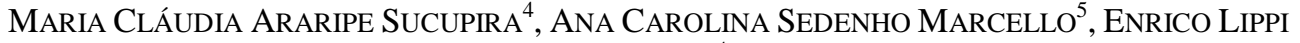 \\ ORTOLANI $^{4}$
}

\footnotetext{
${ }^{1}$ Professor Doutor da Universidade Federal do Vale do São Francisco, Petrolina, PE - Brasil - alexandre.antonelli@ univasf.edu.br ${ }^{2}$ Professor Doutor da Universidade Federal Rural do Semiárido, Mossoro, RN - Brasil.

${ }^{3}$ Especialista em Laboratório da Faculdade de Medicina Veterinária e Zootecnia da USP, São Paulo, SP, Brasil. ${ }^{4}$ Professores Doutores da Faculdade de Medicina Veterinária e Zootecnia da USP, São Paulo, SP, Brasil.

${ }^{5}$ Biomédica Autônoma, Araraquara, SP, Brasil.
}

\begin{abstract}
Seis caprinos divididos aleatoriamente em três grupos foram submetidos a um experimento em Quadrado de Youden (4 X 3), com quatro dietas [controle (C), polpa cítrica (PC), farelo de trigo (FT) e farelo de arroz (FA)], com o objetivo de avaliar qual concentrado predispõe mais à formação de urólitos. Foram analisados os teores séricos de cálcio e fósforo, além do $\mathrm{pH}$, densidade, cálcio e fósforo urinários. A dieta FA apresentou maiores valores séricos e urinários de fósforo $(5,34 \pm 1,71$ e 156,9 $\pm 85,5$ $\mathrm{mmol} / \mathrm{L}$, respectivamente), enquanto que a dieta $\mathrm{PC}$ obteve os teores mais baixos de fósforo no soro e urina
\end{abstract}

\section{RESUMO}

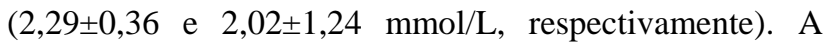
dieta PC resultou em uma urina alcalina $(8,44 \pm 0,33)$, com valores superiores a FT e FA $(6,27 \pm 0,29$ e $6,37 \pm 0,54$, respectivamente). Um animal alimentado com FT e outro com FA apresentaram cristais de fosfato triplo na urina, o que indica um início de formação de cálculo urinário, enquanto que não foram encontrados cristais na urina dos animais alimentados com PC. O fator determinante na formação de cristais é a alta concentração de fósforo na urina. $\mathrm{O}$ pH urinário ácido não impede a formação do urólito se os teores de fósforo urinário estiverem elevados.

PALAVRAS-CHAVE: cálculo urinário; caprinos; farelo de arroz; farelo de trigo; polpa cítrica.

\section{EFFECT OF DIFFERENT ENERGY SOURCES ON PREDISPOSITION OF UROLITHIASIS IN MALE KIDS}

\section{ABSTRACT}

Six goats randomly divided into three groups were used in a 4 X 3 Youden Square design, using four distinct diets [control (C), citric pulp (CP), wheat meal (WM) and rice meal $(\mathrm{RM})]$ in order to evaluate which diet will predispose the formation of uroliths. Serum calcium and phosphorous were determined, as well as urinary $\mathrm{pH}$, density, calcium and phosphorous. The goats fed RM had the highest serum and urinary phosphorous values $(5.34 \pm 1.71$ and $156.9 \pm 85.5 \mathrm{mmol} / \mathrm{L}$, respectively), while the animals that received $\mathrm{CP}$ had the lowest values for blood and urine phosphorous $(2.29 \pm 0.36$ and $2.02 \pm 1.24 \mathrm{mmol} / \mathrm{L}$, respectively). The results of urine $\mathrm{pH}$ showed that $\mathrm{CP}$ diet caused alkaline urine (8.44 \pm 0.33$)$, with higher values than $\mathrm{WM}$ and $\mathrm{RM}(6.27 \pm 0.29$ and $6.37 \pm 0.54$, respectively). The urine from one animal that received WM diet and from another that received RM diet presented triple phosphate crystals, while the urine from the goats receiving $\mathrm{CP}$ did not present any of these crystals. A determinant factor for crystal formation is the high phosphorous concentration in the urine. Acidic urine $\mathrm{pH}$ does not prevent the formation of crystals if urinary phosphorous concentrations are high.

KEYWORDS: citrus pulp; goats; rice meal; urinary calculi; wheat meal. 


\section{INTRODUÇÃO}

A urolitíase é uma enfermidade que ocorre com frequência em ruminantes (TIRUNEH, 2004). Principalmente depois do crescimento da caprinocultura no Brasil e da implementação do sistema de manejo intensivo nas criações, em que se utilizam altas concentrações de dietas concentradas, ocorreu um aumento das enfermidades de origem nutricional e/ou metabólica como a urolitíase.

A formação de cálculos urinários é associada a dietas com altas concentrações de grãos desde meados do século passado (BUSHMAN et al., 1965; HARMON \& BRITTON, 1983; RIET-CORREA et al., 2008), devido ao fato de cereais possuírem baixo teor de cálcio, assim como baixa proporção $\mathrm{Ca}: \mathrm{P}$ (HARMON \& BRITTON, 1983), que resultam em alta ingestão de fósforo dietético com posterior excreção na urina. Em um estudo realizado por BUSHMAN et al. (1965), uma dieta com teores de fósforo de $0,8 \%$ promoveu urolitíase em $73 \%$ dos casos experimentais em ovinos. HARMON \& BRITTON (1983) descreveram a possível relação de dietas com altos teores de grãos que resultam em acidose ruminal interferirem na absorção e excreção de fósforo, cálcio e magnésio, levando ao aumento de fósforo urinário.

Devido à anatomia do sistema urogenital masculino, os machos são mais acometidos pela urolitíase, sendo que os animais castrados mais precocemente são mais predispostos a desenvolver cálculos urinários, pois o desenvolvimento incompleto da uretra leva a um menor diâmetro da mesma, facilitando a obstrução pelos cálculos formados (RIET-CORREA, 2001; AQUINO NETO et al., 2007). A obstrução uretral se caracteriza clinicamente pela retenção urinária, esforços constantes e sem sucesso para urinar, distensão da bexiga e, consequentemente, ruptura da mesma (RADOSTITS et al., 2002; ASSIS et al., 2009).

As causas para a formação do urólito podem ser divididas em três grupos: as que promovem a formação do núcleo do cálculo uretral; as que facilitam a precipitação dos solutos que irão compor o cálculo; e as que favorecem o agrupamento do soluto formando o cálculo uretral. O núcleo é formado, na maioria dos casos, por células epiteliais descamadas onde o depósito de cristais é favorecido. Essa descamação pode ser resultante de infecção no trato urinário ou da deficiência de vitamina $\mathrm{A}$. A alta concentração de determinados minerais na urina pode fazer com que os mesmos se precipitem, favorecendo a formação dos urólitos, assim como o $\mathrm{pH}$ afeta a solubilidade de alguns solutos, em que o
$\mathrm{pH}$ alcalino favorece a formação de cálculos mistos de fosfato e carbonato (RADOSTITS et al., 2002).

Uma medida preventiva para atenuar a formação de cálculos mistos é a adição de substâncias ou produtos que acidifiquem o pH urinário, como o cloreto de amônio. Essa medida promove aumento na excreção de cálcio e magnésio, proporcionando maior solubilidade dos cálculos formados na vesícula urinária. Em estudo feito com caprinos, utilizou-se um suplemento aniônico que promoveu com sucesso a acidificação da urina e aumento na sua excreção, o qual reduziu a probabilidade de surgimento do quadro de urolitíase (STRATTON-PHELPS \& HOUSE, 2004). Mudanças na alimentação e aumento no consumo de água são também medidas profiláticas sugeridas (LORETTI et al., 2003; DEL CLARO et al., 2006).

Vários estudos em pequenos ruminantes foram realizados acerca desse assunto e a literatura é ampla; contudo, a maior parte desta concentra-se em ovinos, sendo mais escassos trabalhos realizados com caprinos. A polpa cítrica é um subproduto da agricultura disponível aos pecuaristas, sendo largamente utilizada na alimentação animal, principalmente para bovinos. Diferente de outras fontes de concentrado mais comumente utilizadas na alimentação animal, a polpa cítrica é rica em energia, tem uma concentração relativamente alta de fibra digestível e contém altos teores de cálcio e baixas quantidades de fósforo na sua composição. Neste trabalho avaliamos principalmente o efeito de diferentes dietas concentradas, incluindo a polpa cítrica desintegrada, em causar a formação de cálculos urinários em caprinos. Este estudo visa, também, comparar o efeito da polpa cítrica desintegrada, do farelo de arroz e do farelo de trigo, sobre a excreção urinária de cálcio e fósforo e a consequente formação de cálculo urinário em cabritos.

\section{MATERIAL E MÉTODOS}

Foram utilizados seis caprinos machos jovens, com idade média aproximada de oito meses, da raça Saanen, castrados há pelo menos três meses, hígidos e com peso vivo médio de $18 \mathrm{~kg}$ ao início do experimento. Os animais foram mantidos nas dependências do Hospital Veterinário da Faculdade de Medicina Veterinária e Zootecnia da Universidade de São Paulo - Campus de Pirassununga - e foram alojados, durante todo o período experimental, em baias que permitiram o controle do consumo alimentar. O projeto foi 
avaliado pelo Comitê de Ética e recebeu o protocolo $n^{\circ} 1524 / 2008$. Os caprinos receberam dieta basal composta exclusivamente por feno de capim coastcross, Cynodon dactlylum (L.) Pers, por quatro semanas antes do início do experimento, sendo que sua composição bromatológica encontra-se na Tabela 1. Água foi fornecida ad libitum durante todo o período experimental.

Os animais foram divididos aleatoriamente em três grupos, com delineamento em Quadrado de Youden (4 X 3), em que foram fornecidas quatro dietas distintas no decorrer do período experimental [controle (C), polpa cítrica (PC), farelo de trigo (FT) e farelo de arroz (FA)], ocorrendo a substituição da dieta a cada 14 dias, sendo que, dessa forma, cada grupo recebeu um tipo de dieta diferente a cada 14 dias. A Tabela 1 apresenta a composição bromatológica dos concentrados e do volumoso e a Tabela 2 apresenta as porcentagens dos ingredientes da dieta total em cada tratamento. A quantidade diária de MS oferecida era equivalente a $2,5 \%$ do peso vivo de cada caprino.

Tabela 1 - Composição bromatológica do feno de coast-cross, farelo de trigo, farelo de arroz e polpa cítrica desintegrada (porcentagem com base na MS)

\begin{tabular}{lccccccccc}
\hline & MS $^{*}$ & PB $^{*}$ & FB $^{*}$ & FDN $^{*}$ & FDA $^{*}$ & EE $^{*}$ & MM $^{*}$ & Ca $^{*}$ & P $^{*}$ \\
\hline Feno de Coast-Cross & 87,47 & 7,48 & 26,66 & 81,22 & 39,66 & 2,13 & 6,45 & 0,42 & 0,15 \\
Farelo de arroz & 88,03 & 14,50 & 10,97 & 29,37 & 18,49 & 16,10 & 7,53 & 0,11 & 1,54 \\
Farelo de trigo & 88,68 & 16,78 & 9,99 & 37,04 & 10,84 & 2,01 & 4,82 & 0,16 & 0,95 \\
Polpa cítrica desintegrada & 85,8 & 7,06 & 12,00 & 21,63 & 27,26 & 2,8 & 9,07 & 1,68 & 0,29 \\
\hline
\end{tabular}

${ }^{*}$ MS - Matéria seca; PB - Proteína bruta; FB - Fibra bruta; FDN - Fibra em detergente neutro; FDA - Fibra em detergente ácido; EE Extrato etéreo; MM - Matéria mineral; Ca - Cálcio; P - Fósforo

Tabela 2 - Composição percentual dos ingredientes utilizados nas dietas (porcentagem com base na MS)

\begin{tabular}{lcccc}
\hline & Controle & Farelo de Arroz & Farelo de Trigo & Polpa Cítrica \\
\hline Feno de Coast-Cross & 100,0 & 50,0 & 50,0 & 50,0 \\
Farelo de arroz & - & 50,0 & - & - \\
Farelo de trigo & - & - & 50,0 & - \\
Polpa cítrica desintegrada & - & - & - & 50,0 \\
\hline
\end{tabular}

Foram realizadas colheitas de sangue e urina ao final de cada duas semanas, o que coincidia com o final de fornecimento de cada dieta, até o término de oito semanas, perfazendo o total de quatro colheitas. As colheitas foram realizadas seis horas após o fornecimento da alimentação aos animais.

Amostras sanguíneas foram colhidas da veia jugular externa, por venipunção, em tubos de vidro siliconizados com vácuo, com gel ativador de coagulação, para obtenção de soro. Foram determinadas as concentrações séricas de magnésio, fósforo e cálcio, utilizando-se kits diagnóstico da marca BioSystems e processando as amostras no analisador bioquímico automático da marca $\mathrm{AMS}^{\circledR}$, modelo Lyasis.

Amostras de urina foram colhidas utilizandose um coletor de urina infantil descartável estéril para uso humano, o qual era fixado ao prepúcio dos caprinos com cola a base de cianoacrilato. Foi determinado o $\mathrm{pH}$ urinário imediatamente após a colheita utilizando-se um potenciômetro digital de mesa (Digimed $^{\circledR}$ - modelo DM-20), assim como a densidade urinária utilizando-se refratômetro portátil. Realizou-se exame de sedimentoscopia para se avaliar os tipos e quantidade de cristais presentes na urina conforme critérios visuais e subjetivos (GARCIA-NAVARRO, 2005). As amostras de urina eram homogeneizadas, em seguida centrifugadas a $400 \mathrm{G}$ por 5 minutos, e o sobrenadante era descartado. O botão de sedimento era suspendido e uma gota dessa suspensão era colocada em uma lâmina de vidro, recoberta com lamínula de vidro de $20 \mathrm{~mm}$ e analisada em microscópio óptico (GARCIA-NAVARRO, 2005). Também foram determinadas as concentrações urinárias de fósforo e cálcio, utilizando-se kit diagnóstico da marca BioSystems e processando as amostras no analisador bioquímico automático da marca $\mathrm{AMS}^{\circledR}$, modelo Lyasis.

Os dados foram analisados utilizando-se ANOVA e as médias foram comparadas utilizandose o teste de Duncan. No estudo de relação entre duas variáveis foram utilizados análise de regressão linear e coeficiente de correlação. Foram 
consideradas diferenças significativas quando $p$ foi inferior a 0,05 . Considerou-se um coeficiente de correlação como de intensidade alta quando $r>0,6$; média se $0,3<\mathrm{r}<0,6$ e baixa no caso de $\mathrm{r}<0,3$ (SAMPAIO, 2002).

\section{RESULTADOS E DISCUSSÂO}

Todos os animais ao início do experimento estavam sadios, alertas, ativos e alimentando-se normalmente, mantendo-se neste estado até o término do período experimental.

Em relação à concentração sérica de cálcio, a dieta de polpa cítrica apresentou valores significativamente maiores $(2,25 \pm 0,15 \mathrm{mmol} / \mathrm{L}) \mathrm{em}$ relação às demais dietas experimentais e à dieta controle. As dietas de farelo de arroz, farelo de trigo e controle não apresentaram diferenças significativas entre si, conforme mostra a Tabela 3.

Tabela 3 - Valores médios e desvio padrão de cálcio e fósforo séricos e de cálcio, fósforo, $\mathrm{pH}$ e densidade urinárias, após 14 dias de alimentação com diferentes dietas

\begin{tabular}{lcccc}
\hline & Controle & Farelo de Arroz & Farelo de Trigo & Polpa Cítrica \\
\hline Cálcio sérico $(\mathrm{mmol} / \mathrm{L})$ & ${ }^{\mathrm{b}} 1,90 \pm 0,19$ & ${ }^{\mathrm{b}} 1,90 \pm 0,26$ & ${ }^{\mathrm{b}} 1,89 \pm 0,21$ & ${ }^{\mathrm{a}} 2,25 \pm 0,15$ \\
Fósforo sérico $(\mathrm{mmol} / \mathrm{L})$ & ${ }^{\mathrm{ab}} 3,10 \pm 0,74$ & ${ }^{\mathrm{a}} 5,34 \pm 1,71$ & ${ }^{\mathrm{a}} 4,65 \pm 1,12$ & ${ }^{\mathrm{b}} 2,29 \pm 0,36$ \\
Magnésio sérico $(\mathrm{mmol} / \mathrm{L})$ & ${ }^{\mathrm{b}} 0,89 \pm 0,04$ & ${ }^{\mathrm{a}} 1,02 \pm 0,05$ & ${ }^{\mathrm{b}} 0,91 \pm 0,03$ & ${ }^{\mathrm{b}} 0,86 \pm 0,03$ \\
$\mathrm{pH}$ urinário & ${ }^{\mathrm{a}} 8,35 \pm 0,25$ & ${ }^{\mathrm{b}} 6,37 \pm 0,54$ & ${ }^{\mathrm{b}} 6,27 \pm 0,29$ & ${ }^{\mathrm{a}} 8,44 \pm 0,33$ \\
Densidade urinária $(\mathrm{g} / \mathrm{dL})$ & ${ }^{\mathrm{a}} 1,015 \pm 0,008$ & ${ }^{\mathrm{a}} 1,026 \pm 0,011$ & ${ }^{\mathrm{a}} 1,021 \pm 0,020$ & ${ }^{\mathrm{a}} 1,018 \pm 0,016$ \\
Cálcio urinário $(\mathrm{mmol} / \mathrm{L})$ & ${ }^{\mathrm{b}} 0,47 \pm 0,41$ & ${ }^{\mathrm{ab}} 2,61 \pm 2,56$ & ${ }^{\mathrm{a}} 2,73 \pm 1,97$ & ${ }^{\mathrm{a} b} 2,02 \pm 1,24$ \\
Fósforo urinário $(\mathrm{mmol} / \mathrm{L})$ & ${ }^{\mathrm{c}} 4,22 \pm 7,60$ & ${ }^{\mathrm{a}} 156,9 \pm 85,5$ & ${ }^{\mathrm{b}} 51,2 \pm 21,2$ & ${ }^{\mathrm{c}} 2,02 \pm 1,24$ \\
\hline
\end{tabular}

Letras distintas na mesma linha indicam diferenças significativas entre os grupos $(p<0,05)$.

Os valores médios de fósforo sérico obtidos na dieta de Farelo de Arroz $(5,34 \pm 1,71 \mathrm{mmol} / \mathrm{L})$ e com a dieta com Farelo de Trigo $(4,65 \pm 1,12$ $\mathrm{mmol} / \mathrm{L}$ ) foram semelhantes entre si e superiores aos teores médios obtidos na dieta com polpa cítrica $(2,29 \pm 0,36 \mathrm{mmol} / \mathrm{L})$. A dieta controle $(3,10 \pm 0,74$ $\mathrm{mmol} / \mathrm{L}$ ) não apresentou diferença significativa quando comparada com as demais dietas experimentais (Tabela 3).

Quando analisados os teores séricos de magnésio, observou-se que os valores mais altos foram obtidos quando os animais receberam a dieta de farelo de arroz $(1,02 \pm 0,05 \mathrm{mmol} / \mathrm{L})$, não havendo diferença significativa entre as dietas controle, farelo de trigo e polpa cítrica $(0,89 \pm 0,04 \mathrm{mmol} / \mathrm{L}$, $0,91 \pm 0,03 \mathrm{mmol} / \mathrm{L}$ e $0,86 \pm 0,03 \mathrm{mmol} / \mathrm{L}$, respectivamente) (Tabela 3 ).

A análise do $\mathrm{pH}$ urinário mostrou que a urina dos animais que receberam as dietas de farelo de trigo e farelo de arroz $(6,27 \pm 0,29$ e $6,37 \pm 0,54$, respectivamente) apresentava-se levemente acidificada e mais baixa que o $\mathrm{pH}$ da urina dos caprinos, que apresentava-se alcalina, quando alimentados com polpa cítrica ou dieta controle $(8,44 \pm 0,33$ e $8,35 \pm 0,25$, respectivamente). A densidade urinária não apresentou variação significativa entre as dietas experimentais, bem como em relação à dieta controle $(p>0,10)$ (Tabela 3$)$.

Ao se avaliarem os valores médios de cálcio urinário, observou-se que, nos animais que receberam farelo de trigo, houve maior excreção deste elemento na urina $(2,73 \pm 1,97 \mathrm{mmol} / \mathrm{L}) \mathrm{em}$ relação à dieta controle $(0,47 \pm 0,41 \mathrm{mmol} / \mathrm{L})$ (Tabela 3). $\mathrm{Na}$ análise dos teores de fósforo urinário, a dieta contendo farelo de arroz resultou em maior excreção de fósforo $(156,9 \pm 85,5 \mathrm{mmol} / \mathrm{L})$ em relação às demais dietas, sendo que a dieta de farelo de trigo apresentou valores intermediários $(51,2 \pm 21,2$ $\mathrm{mmol} / \mathrm{L}$ ), mas ainda superiores aos apresentados pelas dietas com polpa cítrica e controle $(2,02 \pm 1,24 \mathrm{e}$ 4,22 $\pm 7,60 \mathrm{mmol} / \mathrm{L}$, respectivamente) (Tabela 3 ).

$\mathrm{Na}$ análise da relação entre o fósforo sérico e sua excreção urinária, ocorreu uma expressiva correlação positiva $(\mathrm{r}=0,71 ; p<0,05)$. Já a relação entre cálcio sérico e urinário foi de baixa correlação $(\mathrm{r}=0,28 ; p<0,05)$. Ao se analisar a relação entre o cálcio sérico e o fósforo sérico, obteve-se uma alta correlação negativa $(r=-0,70$; $p<0,05)$, enquanto que a relação entre o cálcio sérico e o fósforo urinário foi apenas de média expressão $(\mathrm{r}=-0,46 ; p<0,05)$. A relação entre o $\mathrm{pH}$ urinário e o fósforo urinário apresentou uma correlação negativa alta $(\mathrm{r}=-0,69 ; p<0,05)$ (Figura 1). 


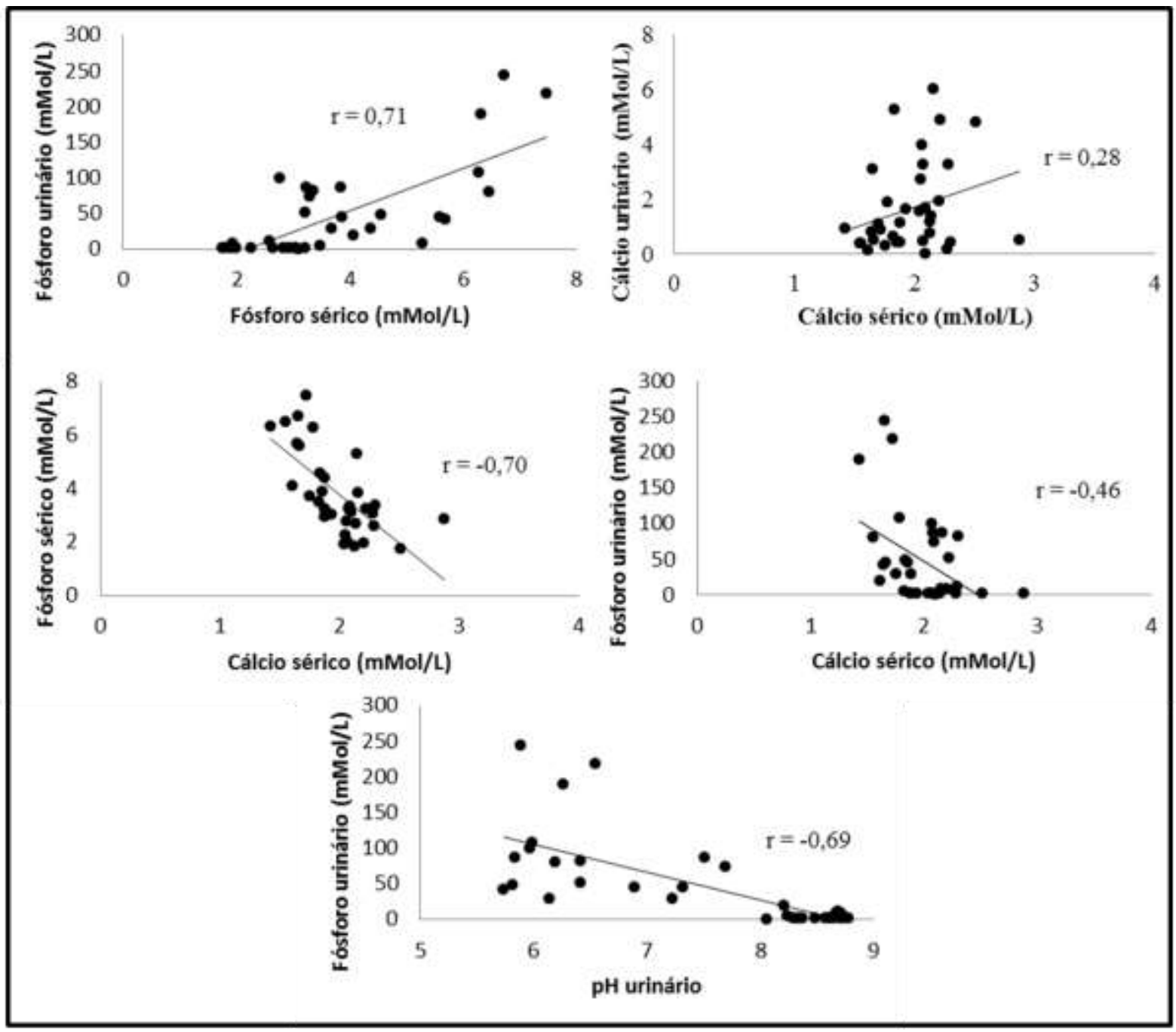

Figura 1 - Análise das relações entre fósforo sérico e urinário, cálcio sérico e urinário, cálcio e fósforo séricos, cálcio sérico e fósforo urinário, e entre pH e fósforo urinários.

$\mathrm{Na}$ avaliação microscópica da urina para se determinarem os tipos e quantidade de cristais presentes na urina, verificou-se que, antes do início do período experimental, não foi encontrado nenhum tipo de cristal na urina. Um cabrito alimentado com farelo de arroz e outro que recebeu farelo de trigo como concentrado apresentaram alta quantidade de cristais de fosfato triplo na urina (Tabela 4).
Também foi constatada a presença moderada de cristais de ácido hipúrico na urina de um caprino alimentado com farelo de arroz e de outro animal alimentado com farelo de trigo. Nenhum animal apresentou cristais na urina após o período em que foi alimentado com a dieta controle ou com polpa cítrica.

Tabela 4 - Quantidade de cristais presentes na urina e frequência de animais que apresentaram cristais após 14 dias de alimentação com diferentes dietas

\begin{tabular}{lll}
\hline & Cristal de Fosfato Triplo & Cristal de Ácido Hipúrico \\
\hline Controle & Nenhum $(0 / 6)$ & Nenhum $(0 / 6)$ \\
Farelo de arroz & Alta (1/6) & Baixa $(1 / 6)$ \\
Farelo de trigo & Alta $(1 / 6)$ & Baixa $(1 / 6)$ \\
Polpa cítrica & Nenhum $(0 / 6)$ & Nenhum $(0 / 6)$ \\
\hline
\end{tabular}


O presente experimento confirmou as expectativas de que a oferta de polpa cítrica na dieta de caprinos resultaria em menor predisposição à formação de cálculos urinários. Embora não tenham ocorrido formações de cálculos, no computo geral do aparecimento de cristais formadores de urólitos e as concentrações séricas e urinárias de fósforo evidenciaram que a polpa cítrica predispõe menos os caprinos à urolitíase do que o farelo de trigo ou farelo de arroz (Tabelas 2 e 3), com efeitos urinários semelhantes à dieta exclusiva com volumoso (controle). A formação de fosfato triplo na urina apenas dos animais que receberam dietas contendo farelo de trigo e farelo de arroz está relacionada às altas concentrações séricas e urinárias de fósforo.

Em um estudo, dietas com teores de fósforo acima de 0,57\% na MS (GIANESELLA et al., 2010) em sua composição predispuseram à formação de cálculos urinários devido ao aumento do teor sérico de fósforo e sua consequente excreção urinária. Vários autores (GODWIN \& WILLIAMS, 1982; SINGH et al., 2008; SACCO \& LOPES, 2011) também mostraram que há uma relação direta entre a alta concentração de fósforo urinário e maior formação de urólitos. Ao compararmos os valores médios dos teores séricos de fósforo dos animais alimentados com polpa cítrica desintegrada com as outras duas dietas experimentais, verificamos valores mais baixos e próximos aos da dieta controle. Esses valores mais baixos de fósforo sérico são semelhantes aos resultados obtidos por OLIVEIRA et al. (2005) em um estudo realizado com bovinos alimentados com polpa cítrica peletizada. Os teores elevados de fósforo sérico nas dietas de farelo de trigo e farelo de arroz refletem as suas composições bromatológicas, como se pode verificar na Tabela 1.

Outros fatores relacionados à urolitíase, além dos altos teores de fósforo sérico, são os valores elevados de magnésio e baixos teores de cálcio séricos (KUNKEL et al., 1961). Neste estudo, também foi verificado que a dieta composta de farelo de arroz resultou em teores séricos de fósforo elevados e baixa concentração de cálcio (Tabela 2), comparado à tabela de referência $(\mathrm{Ca}-2,58 \pm 1,12$ $\mathrm{mmol} / \mathrm{L} ; \mathrm{P}-4,65 \pm 1,12 \mathrm{mmol} / \mathrm{L} ; \mathrm{Mg}-1,32 \pm 0,14$ mmol/L - KANEKO et al., 2008). Já os caprinos que foram alimentados com polpa cítrica apresentaram um teor médio de cálcio sérico superior aos das dietas controle, farelo de trigo e farelo de arroz, resultado que concorda com o encontrado por OLIVEIRA et al. (2005) para cálcio sérico em bovinos alimentados com polpa cítrica.

Apesar de estudos apontarem o $\mathrm{pH}$ alcalino como sendo o fator mais predisponente para a formação do cálculo urinário à base de fosfatos
(CROOKSHANK et al., 1960), os resultados deste trabalho mostraram que a influência da concentração urinária de fósforo é maior que a do $\mathrm{pH}$ para a formação de urólitos de cristais de fosfatos. Conclusão semelhante foi feita por UDALL \& CHOW (1963), ao afirmar que a formação de cálculos urinários ocorre tanto em $\mathrm{pH}$ ácido como alcalino. Nas dietas de farelo de trigo e farelo de arroz, que apresentaram um $\mathrm{pH}$ urinário ligeiramente ácido, os altos teores de fósforo na urina levaram à formação de cristais de fosfato triplo em pelo menos dois animais neste período experimental, comprovado pela alta correlação negativa entre o pH urinário e a concentração urinária de fósforo.

\section{CONCLUSÕES}

O fornecimento de polpa cítrica desintegrada na dieta de caprinos mostrou-se, neste estudo, ter potencial menos calculogênico que o farelo de arroz e o farelo de trigo, na proporção de $50 \%$ da MS total da dieta. O fator determinante na formação de cristais que irão compor o cálculo urinário é a elevada concentração de fósforo na urina que é altamente correlacionada de forma positiva com o fósforo sérico. $\mathrm{O} \mathrm{pH}$ urinário ácido não impede a formação do urólito se os teores de fósforo urinário estiverem elevados.

\section{REFERÊNCIAS}

AQUINO NETO, H. M.; FACURY FILHO, E. J.; CARVALHO, A. U.; SOUZA, F. A.; JORDÃO, L. R. Urolitíase obstrutiva em ovinos: revisão de literatura. Veterinária em Foco, v. 4, n. 2, p. 191-202, 2007.

ASSIS, A. C. O.; SILVA, T. R.; AGUIAR, G. M. N.; MELO, D. B.; ALMEIDA, F. C.; MEDEIROS, J. M.; NÓBREGA NETO, P. I. Urolitíase obstrutiva em bovinos no semi-árido paraibano. Ciência Animal Brasileira, v. 10, supl. 1, p. 41-45, 2009.

BUSHMAN, D. H.; EMERICK, R. J.; EMBRY, L. B. Incidence of urinary calculi in sheep affected by various dietary phosphates. Journal of Animal Science, v. 24, n. 3, p. 671-675, 1965.

CROOKSHANK, H. R.; KEATING, F. E.; BURNETT, E.; JONES, J. H.; DAVIS, R. E. Effect of chemical and enzymatic agents on the formation of urinary calculi in fattening steers. Journal of Animal Science, v. 19, n. 2, p. 595-600, 1960.

DEL CLARO, G. R.; ZANETTI, M. A.; CORREA, L. B.; NETTO, A. S.; PAIVA, F. A.; SALlES, M. S. V. Balanço cátion-aniônico da dieta no metabolismo de cálcio em ovinos. Ciência Rural, v. 36, n. 1, p.222-228, 2006. 
GARCIA-NAVARRO, C. E. K. Manual de urinálise veterinária. São Paulo: Varela, 2005. 95 p.

GIANESELLA, M.; GIUDICE, E.; MESSINA, V.; CANNIZZO, C.; FLORIAN, E.; PICCIONE, G.; MORGANTE, M. Effect of an unbalanced $\mathrm{Ca} / \mathrm{P}$ diet on blood parameters and urolithiasis in growing calves. Veterinarija ir Zootechnika, v. 49, n. 71, p.32-36, 2010.

GODWIN, I. R.; WILLIAMS, V. J. Urinary calculi formation in sheep on high wheat grain diets. Australian Journal of Agricultural Research, v. 33, n. 5, p. 843$855,1982$.

HARMON, D. L.; BRITTON, R. A. Balance and urinary excretion of calcium, magnesium and phosphorus in response to high concentrate feeding and lactate infusion in lambs. Journal of Animal Science, v. 57, n. 5, p. 1306$1315,1983$.

KANEKO, J. J.; HARVEY, J. W.; BRUSS, M. L. Clinical Biochemistry of Domestic Animals. San Diego: Academic Press, 2008. 932 p.

KUNKEL, H. O.; WHITAKER, E. S.; PACKETT JUNIOR, L. V.; CROOKSHANK, H. R. Relationship of serum magnesium, cadmium and phosphorous to incidence of urinary calculi in lambs. Journal of Animal Science, v. 20, n. 4, p. 940, 1961.

LORETTI, A. P.; OLIVEIRA, L. O.; CRUZ, C. E. F.; DRIEMEIER, D. Clinical and pathological study of an outbreak of obstructive urolithiasis in feedlot cattle in southern Brazil. Pesquisa Veterinária Brasileira, v. 23, n. 2 , p. $61-64,2003$

OLIVEIRA, N. J. F.; MELO, M. M.; LAGO, L. A.; NASCIMENTO, E. F. Hemograma, bioquímica sérica e histologia da biópsia hepática de bovinos após administração de polpa cítrica. Arquivo Brasileiro de Medicina Veterinária e Zootecnia, v. 57, n. 3, p. 418422, 2005.

RADOSTITS, O. M.; GAY, C. C.; BLOOD, D. C.;
HINCHCLIFF, K. W. Clínica veterinária: um tratado de doenças dos bovinos, ovinos, suínos, caprinos e eqüinos. 9. ed. Rio de Janeiro: Guanabara Koogan, 2002. 1737 p.

RIET-CORREA, F.; SIMÕES, S. V. D.; VASCONCELOS, J. S. Urolitíase em caprinos e ovinos. Pesquisa Veterinária Brasileira, v. 28, n. 6, p. 319-322, 2008.

RIET-CORREA, F. Urolitíase em ruminantes. In: RIETCORREA, F.; SCHILD, A. L.; MENDEZ, M.C.; LEMOS, A. Doenças de ruminantes e equinos - volume 2. $2^{\text {a }}$ ed. São Paulo: Varela, 2001, p. 561-565.

SACCO, S. R.; LOPES, R. S. Urolitíase: estudo comparativo em bovinos Guzerá oriundos de propriedades com e sem o problema. Pesquisa Veterinária Brasileira, v. 31, n. 3, p. 206-212, 2011.

SAMPAIO, I. B. M. Estatística aplicada à experimentação animal. Belo Horizonte: Fundação de Ensino e Pesquisa em Medicina Veterinária e Zootécnica, 2002. $265 \mathrm{p}$.

SINGH, T.; AMARPAL; KINJAVDEKAR, P.; AITHAL, H. P.; PAWDE, A. M.; PRATAP, K.; MUKHERJEE R. Obstructive urolithiasis in domestic animals: A study on pattern of occurrence and etiology. The Indian Journal of Animal Sciences, v. 78, n. 6, p. 599-603, 2008.

STRATTON-PHELPS, M.; HOUSE, J. K. Effect of a commercial anion dietary supplement on acid-base balance, urine volume, and urinary ion excretion in male goats fed oat or grass hay diets. American Journal of Veterinary Research, v. 65, n. 10, p. 1391-1397, 2004.

TIRUNEH, R. Minerals and Oxalate content of feed and water in relation with ruminant urolithiasis in Adea district, central Ethiopia. Revue de Médecine Vétérinaire, v. 156, n. 5, p. 272-277, 2004.

UDALL, R. H.; CHOW, F. C. Ion-competition and the formation of phosphatic uroliths. Annals of New York Academy of Sciences, v. 104, n. 5, p. 612-620, 1963. 